\title{
An Engineering Model for Polymer Electrolyte Membrane Fuel Cells
}

\author{
T.A.Š uker ${ }^{1}$, B.J.Holland ${ }^{2}$, J.G. Zhu ${ }^{3}$ \\ Faculty of Engineering \\ University of Technology, Sydney \\ PO. Box 123, Broadway 2007, Australia \\ Tel: (02) 9514 2337, Fax: (02) 95142435 \\ e-mail: tadijica.suker@eng.uts.edu.au ${ }^{1}$; $\underline{\text { brett.holland@eng.uts.edu.au }}^{2}$; joe@eng.uts.edu.au ${ }^{3}$
}

\begin{abstract}
The Polymer Electrolyte Membrane (PEM) fuel cell model proposed incorporates analytical based and empirical based equations. The model is based on a comprehensive literature survey and comparative study of fuel cell modelling. Both perspectives, analytical and empirical are taken into consideration. In addition the advantages of the dynamic simulation compared to the steady state simulation are specified.
\end{abstract}

\section{Key words}

Fuel Cells, PEM, Models, Simulation, Hydrogen

\section{Introduction}

Polymer Electrolyte Membrane (PEM) fuel cells are suitable for electrical vehicle and other mobile applications because of their special features such as high efficiency and high power density. In order to make best use of PEM fuel cells in practical applications, an accurate and practical model is required to simulate the fuel cell performance in system design.

This work includes the introduction of an engineering model, which is particularly suited to the engineering design and application of PEM fuel cells. The analytical data and experimental procedures required for determining the parameter values used in the model are specified and validated

\section{Model review}

At the beginning of research in simulation the interest was to model the transient behaviour of PEM fuel cells for the steady state. Therefore several electrochemical models which predicted the steady state behaviour of fuel cells by estimating the cell voltage for a particular set of operating conditions have been used in the past. These operating conditions included reactant gas concentrations, pressures, and operating current.
Those models satisfied the need for modelling the behaviour of a PEM fuel cell in a stationary power application.

For PEM fuel cells in transportation and portable applications again the unsteady state behaviour is becoming more an issue because the operating conditions will normally change with time. For example, system start-up, system shut-down, and large changes in the power level will be accompanied by changes in the stack temperature and changes in the reactant gas concentrations at the electrode surface. Therefore, both mass and heat transfer features must be incorporated into an electrochemical model to form an overall model predicting behaviour responses by the stack.

In general any model used for simulation can became very complex and the results can be faulty. Due to that it is very important to know what the output of a simulation has to be like or at least to have an idea about its range. That is why simulation is a kind of paradox.

In order to know which parameters are necessary to simulate it is essential to know which parameters are influencing the performance of a fuel cell and even more important is to know how great their influence is. Thus the amount of parameters which have to be considered for the simulation depends greatly on the requested accuracy for the simulation. That is why models can range from simple to complex. The simpler models are usually based on idealized processes and require few parameters. The more complex models are usually more detailed and more accurate but therefore they require a much greater number of parameters.

\section{Simulation technique}

One of the simulation techniques is the modular simulation technique. The modular simulation technique can be either empirical or analytical based. Main advantage of the modular simulation technique compared with the system simulation technique is the reduction of the complexity by reducing a large problem of a whole system into a number of smaller problems and each of them can be solved more easily. 


\section{PEMFC electro-chemistry}

The fuel cell stack voltage is determined by subtracting the various overvoltages from the reversible voltage $(E)$ as shown in equation (1).

The main overvoltages are the ohmic, activation and concentration overvoltage.

Vstack $=E-$ Vohm.overv. - Vact.overv. - Vcon.ocerv.

In Fig. 1 it is the polarization curve is shown with the different areas influenced by the main overvoltages.

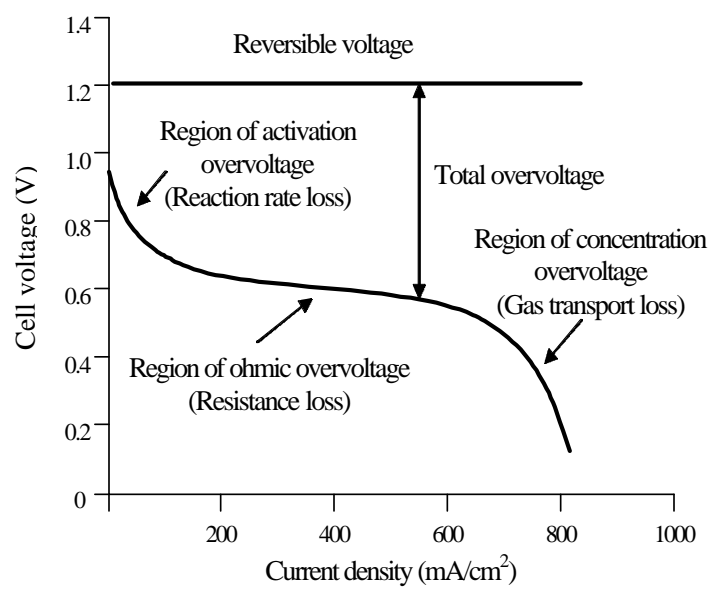

Fig.1 PEM fuel cell polarization curve

\subsection{Reversible voltage}

The change in Gibbs free energy on which the reversible voltage depends varies with different partial pressures of the hydrogen fuel and the oxidant. The reversible voltage at $\operatorname{STP}\left(E^{0}\right)$ is $1.23 \mathrm{~V}$. Assuming ideal gases the reversible voltage at standard pressure the Nernst Equation for the overall reaction in a PEM fuel cell $\left(\mathrm{H}_{2}+1 / 2 \mathrm{Q} \quad \mathrm{H} \quad 2 \mathrm{O}\right)$ can be used for varying pressure like it is shown in (2).

$$
E=E^{0}+\frac{R T}{2 F} \ln \left[\frac{p_{\mathrm{H}_{2}}^{*}\left(p_{\mathrm{O}_{2}}\right)^{*}}{p_{\mathrm{H}_{2} \mathrm{O}}{ }^{\frac{1}{2}}}\right]
$$

It is possible to simplify this equation by considering the partial pressure for water $\left(P_{\mathrm{H}_{2} \mathrm{O}}\right)$ to be 1 bar. The simplified equation can be written as:

$$
E=E^{0}+\frac{R T}{2 F} \ln \left[\dot{P_{H_{23}}} *\left(\dot{P}_{O_{2}}\right)^{\frac{1}{2}}\right]
$$

Rewriting (3) including all values for the different constants gives following equation:

$$
E=1.23+\left(4.31 * 10^{-5}\right) \ln \left[\dot{P_{H_{23}}} *\left(\dot{P_{O_{2}}}\right)^{\frac{1}{2}}\right]
$$

Equation (4) is accurate as long the temperature is $298 \mathrm{~K}$. As soon the Temperature changes it is necessary to add a term for the variation in temperature which is:

$$
E_{T}=\ddot{A} S / 2 F\left(T-T_{S C}\right)
$$

Rewriting (3) including (5) and all values for the different constants gives us the equation which is going to be used for the PEM fuel cell model to calculate the reversible voltage:

$$
E=1.23+\left(4.31 * 10^{-5}\right) \ln \left[\dot{P_{H_{23}}} *\left(\dot{P_{O_{2}}}\right)^{\frac{1}{2}}\right]-8.5 * 10^{-4} *(T-298)
$$

\subsection{Activation overvoltage}

It is called an activation overvoltage because it relates to the activation energy required at both the anode and cathode of the fuel cell. The activation overvoltage is caused by limited reaction rates at the surface of the electrodes, and is dominant at low current density and increases only slightly with an increase of the current density. In a PEM fuel cell the activation loss at the Anode is much smaller than at the Cathode that is why it is often neglected. The chemical processes of the activation overvoltage are complex.

$$
\begin{aligned}
V_{\text {act.overv. }}= & \delta_{1} T \ln (i)+\delta_{2}+\delta_{3} T+\delta_{4} T \ln \left(C_{O_{2}}\right) \\
& +\delta_{5} T \ln \left(C_{H_{2}}\right)
\end{aligned}
$$

The physical meaning of $\delta_{1}, \delta_{2}, \delta_{3}, \delta_{4}, \delta_{5}$ are: [6]

$$
\begin{gathered}
\delta_{1}=\frac{R}{2 \alpha_{c} F}+\frac{R}{2 \alpha_{a} F} \\
\delta_{2}=\frac{\Delta F_{c}}{2 \alpha_{c} F}+\frac{\Delta F_{e c}}{2 \alpha_{a} F} \\
\delta_{3}=-\left(\frac{R \ln \left(n_{c} F A k^{0}\right)}{2 \alpha_{c} F} C_{\text {proton }^{1-\alpha_{c}} C_{H_{2} O}{ }^{\alpha_{c}}}\right) \\
\delta_{4}=-\frac{R\left(1-\alpha_{c}\right)}{2 \alpha_{c} F} \\
\delta_{5}-\left(\frac{R \ln \left(n_{a} F A k^{0}\right)}{2 \alpha_{a} F}\right)
\end{gathered}
$$

The constants $F$ and $R$ are known and $n_{a}, n_{c} \Delta F_{c}, \Delta F_{e c}$ and $C_{H^{2} \mathrm{O}}$ are constants that are initially unknown. The parameters $\alpha_{a}, \alpha_{c}, k_{a}{ }^{0} k_{c}{ }^{0}$ and $C_{\text {proton }}$ are approximately constant for the reaction and assumed to be constant [6]. 


\subsection{Ohmic overvoltage}

Ohmic overvoltage is caused by the flow of ions through the resistance of the PEM and by the flow of electrons through the resistance of the electrodes. This overvoltage is directly proportional to the current density $(j)$ and depends on the water concentration in the membrane and its temperature. The ohmic overvoltage can be defined by ratios between the current density with the PEM thickness $\left(P E M_{t}\right)$ and with the hydration of the PEM (a) like in (13): [3]

$$
V_{\text {ohm.overv. }}=\left(j * P E M_{t}\right) *(a * T) *(\hat{a} * j) *\left(\tilde{a} * j^{3}\right)
$$

The constants $a$ and $\hat{a}$ are empirical based.

\subsection{Concentration overvoltage}

The simulation of the concentration overvoltage does not improve the accuracy of the PEMFC model because the overvoltage caused by the reduction of gas concentration accurse in the polarisation curve of a PEM fuel cell behind the Maximum Power Point (MPP) like it is shown in Fig.2. The PEM fuel cell is never going to be operated behind the MPP as for the same power output a much higher current density would be necessary.

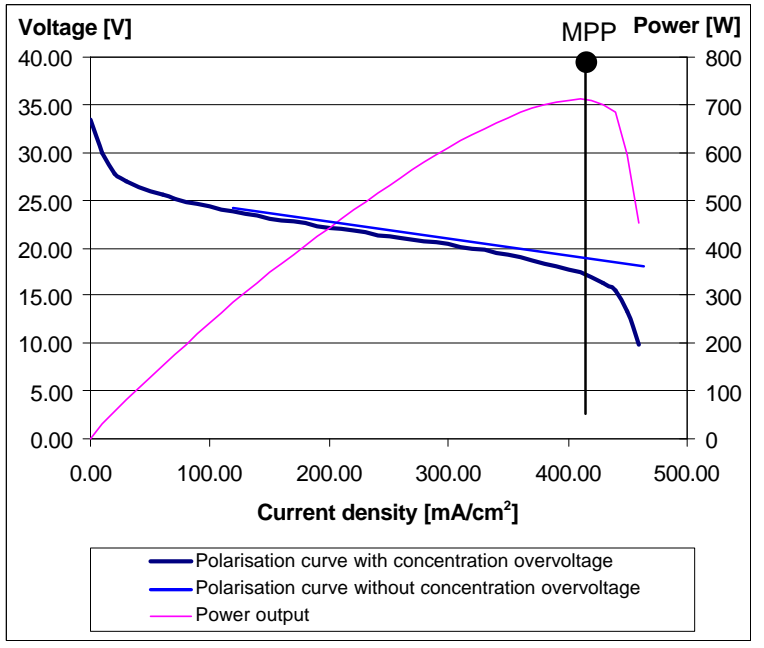

Fig.2 PEMFC polarization curve

\section{Simulation work space}

For the simulation work space the program TRNSYS (Transient System Simulation Program) is very suitable. TRNSYS is a modular simulation program based on the problem-oriented language FORTRAN. The modular structure of TRNSYS gives the programmer enormous flexibility and makes it easy for users to add their own models to the TRNSYS library. The standard TRNSYS library includes many of the components commonly found in thermal and electrical renewable energy systems. The program is well suited to perform detailed analyses of PEM fuel cell systems. Included with the TRNSYS program is the utility program IISiBat.

TRNSYS is able to simulate the PEM Fuel Cell with its complex chemical reactions as a part of a complete energy system including for example fuel storage, auxiliary heater, and electrical load.

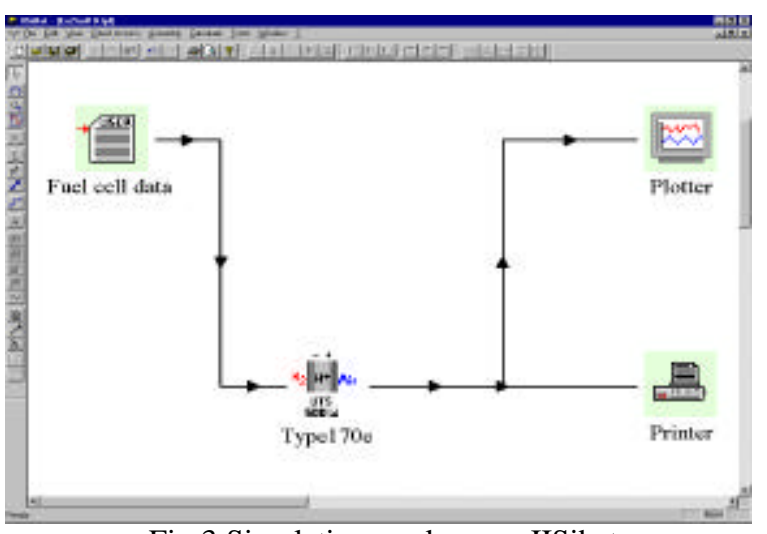

Fig.3 Simulation work space IISibat

\section{Model of the PEM fuel cell}

PEM fuel cells are complex systems and are difficult to be modelled only analytically. The model for the PEM fuel cell is mainly based on theory but includes some empirical based features. In order to increase the analytical part of the model we tried to take even the internal current into consideration which allows a more precisely model for low temperature PEM fuel cells. [3]

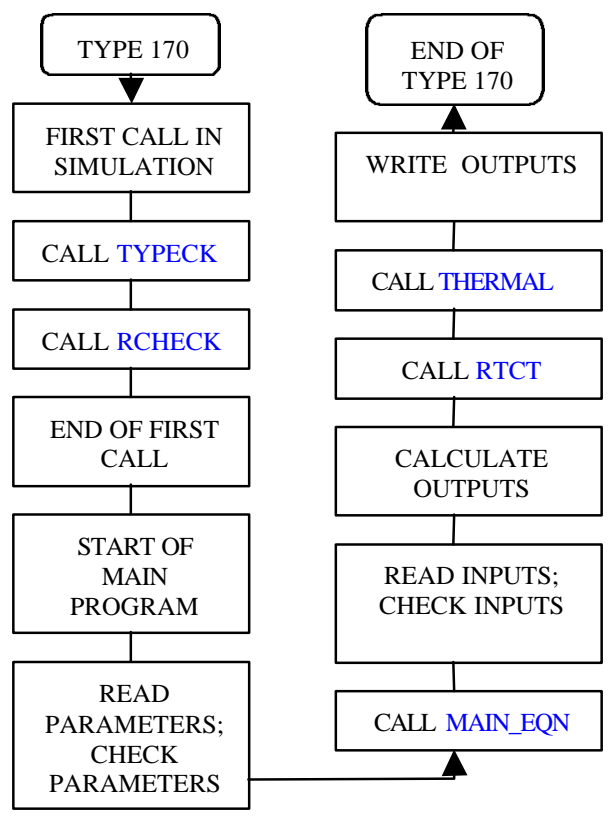

Fig.4 Flow process chart

Most terms in the PEM fuel cell model are derived from theory or include coefficients that have a theoretical basis. The three main Parameters required by the electrochemical part of the model is the cross-sectional electrode area of the membrane, membrane thickness, and a coefficient ã representing the transport number for water in the membrane. Further system design parameters, such as the number of cells in series per stack and the number of stacks in parallel per unit, must be 
supplied. The thermal dynamic part of the model requires only two parameters, the overall thermal resistance $\left(\mathrm{R}_{\mathrm{t}}\right)$ and thermal capacitance $\left(C_{t}\right)$ also included in the PEM fuel cell model is an option where $R_{t}$ and $C_{t}$ are calculated.

The membrane electrode assembly (MEA) of the PEM fuel cell is assumed to consists of a membrane and two electrodes (Anode and Cathode), which are made mainly of graphite, while the supporting structure (e.g. End plates) is assumed to be made of stainless steel.

\section{Evaluation of the steady state behaviour}

The steady state performance of the PEM fuel cell stack is expressed by the polarisation curve (Fig.5). A steady state model can be used to predict the polarisation curve, and hence the steady state performance of the PEM fuel cell stack.

Following factors are particularly important:

- Gas mass flows (pressure and stoichiometry of the inlet gases),

- Operating temperature of the fuel cell stack an

-Relative humidity of the reactant gases, primarily of the anode gas.

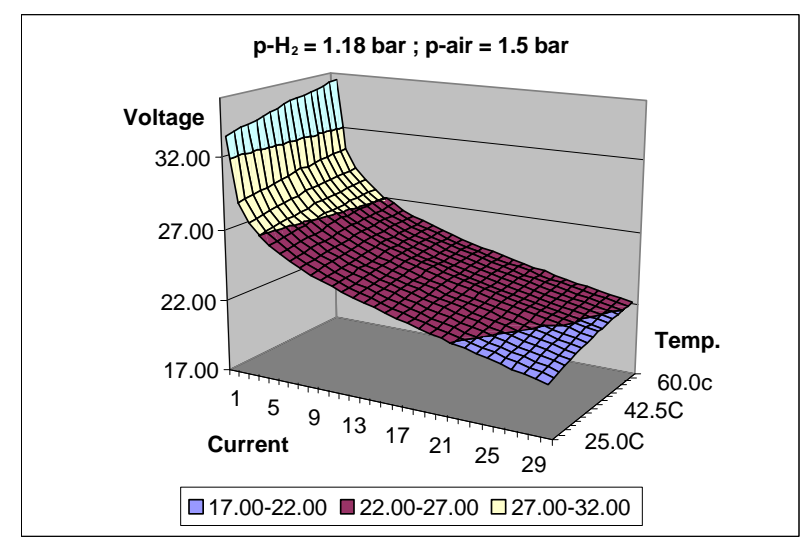

Fig.5 Dependency between polarisation curve and the inlet pressures

\section{Evaluation of the dynamic behaviour}

In order to evaluate the behaviour of the fuel cell model during the warm-up and cool-down sequence we create in IISiBat a circuit including the PEM fuel cell model.

In Fig. 6 it is shown that at the beginning of the simulation the fuel cell temperature straight to the fuel cell set point temperature jumps. The fuel cell temperature remains constant even in case the current density changes or the fuel cell is switched off. With the change in current density the fuel cell voltage changes simultaneous. The auxiliary heating or cooling demand (Q_diff) changes with the current density as well and its value is always equal to the amount of cooling (positive) or heating (negative) which is necessary to keep the fuel cell temperature constant. In case the fuel cell is switched of the current density drops immediately and the fuel cell voltage rise to its open circuit voltage. The fuel cell temperature drops slowly till it reaches the ambient temperature.
Overall the dynamic behaviour of the PEM fuel cell in the area of operations is sufficient but its dynamic behaviour during the start-up and shut-down sequence has to be improved.

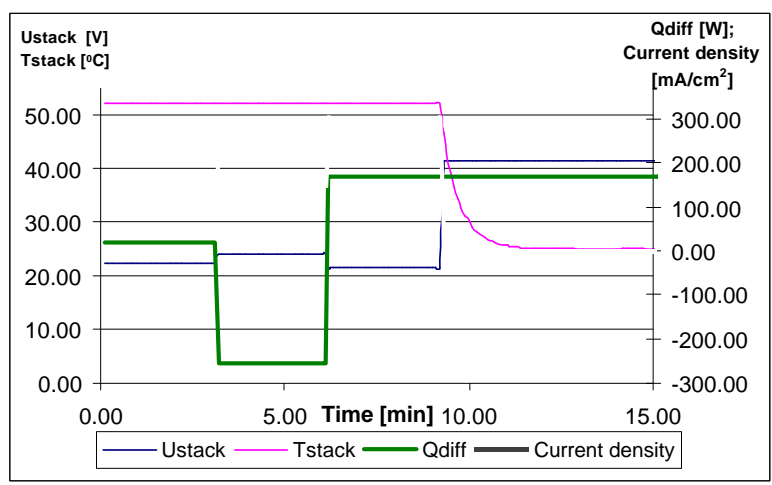

Fig.6 Dynamic behaviour of the fuel cell model

\section{Conclusion}

This paper gives a detailed review on PEM fuel cell modelling and describes a proposed simulation model. The steady state and dynamic performance has been accurately described in form of polarisation curves. The proposed model has been used to predict the performance of a 500W PEM fuel cell under varied conditions.

\section{Acknowledgement}

The work described in this paper has been supported by the German Academic Exchange Service (DAAD) and by the Australian Cooperative Research Centre for Renewable Energy (ACRE). Tadijica Šuker has been supported by a DAAD Postgraduate Research Scholarship and Brett Holland has been supported by an ACRE Postgraduate Research Scholarship.

\section{References}

[1] Amphlett J.C., Baumert R.M., Mann R.F., Peppley B.A. and Roberger P.R. 1995

'Performance Modelling of the Ballard Mark IV Solid Polymer Electrolyte Fuel Cell II. Empirical Model Development', Journal of the Electrochemical Society Vol 142, pp.9-15.

[2] Mann R.F., Amphelett J.C., Hooper M.A.I., Heidi M.J., Peppley B.A. and Roberger P.R. 1999 'Development and application of a generalised steady-state electrochemical model for a PEM fuel cell' Journal of Power Sources 86 (2000) pp.173-180

[3] Ulleberg Ø. 1998 'Stand-Alone Power System for the future: Optimal Design, Operation \& Control of Solar-Hydrogen Energy Systems', Ph.D. dissertation Norwegian University of Science and Technology Trondheim

[4] Ulleberg Ø., Glöckner R., "Hydrogems - Hydrogen energy Models", WHEC 2002 - 14th World Hydrogen Energy Conference, Montreal, 9-13 June 2002.

[5] Balkin A., Holland B., Zhu J., "Modelling Polymer Electrolyte Membrane Fuel Cells", AUPEC 2002, Australasian University Power Engineering Conference,Melbourne, 30th September - 2nd October 2002. 


\section{APPENDIX}

$\alpha \quad$ Charge transfer coefficient of the anode or cathode

$\Delta \mathrm{F}_{\mathrm{e}} \quad$ Standard free energy of activation for the cathode reaction

$\Delta \mathrm{F}_{\mathrm{ec}} \quad$ Standard free energy of activation for chemical absorption

$\Delta h$

$\Delta s$

$\delta_{m}$

$\varepsilon_{m}$

$B$

$\mathrm{Cd}$

$C_{m}$

$$
\begin{gathered}
\text { Concentration of } \mathrm{H}_{2} \mathrm{O}_{2} \text { or } \mathrm{H}_{2} \mathrm{O} \text { or the } \\
\text { total concentration of protons in the } \\
\text { membrane }
\end{gathered}
$$
Faraday's constant

Current of the fuel cell or stack (A) Limiting current for the concentration loss of the stack (A)

Internal current of the stack (A)

Exchange current of the fuel cell at the anode or cathode (A)

Current density of the fuel cell or stack $\left(\mathrm{A} / \mathrm{cm}^{2}\right)$

$k_{m}{ }^{0} \quad$ Intrinsic Rate constant for the anodic or cathodic reaction

\author{
$m_{K} \quad$ Concentration loss coefficient (mV) \\ $n_{m} \quad$ Number of electrons transferred per \\ mole of the electrolysed component of \\ the anodic or cathodic reaction \\ $N_{\text {cell }} \quad$ Number of cells in the stack \\ $n_{K} \quad$ Concentration loss coefficient $\left(\mathrm{cm}^{2} /\right.$ \\ $\mathrm{mA}$ ) \\ * Partial pressure of species $x$ \\ $p_{x}$ \\ $R \quad$ Universal gas constant \\ $R_{a c t} \quad$ Activation equivalent resistance \\ $R_{\text {ohmic }} \quad$ Total resistance of the fuel cell stack \\ $(\Omega)$ \\ $R_{\text {cell,K}} \quad$ Ohmic resistance $\left(\Omega . \mathrm{cm}^{2}\right)$ from Kim et \\ al. \\ $T \quad$ Temperature of the fuel cell (K) \\ $E^{0} \quad$ Reversible fuel cell voltage at STP \\ $E \quad$ Open circuit potential of the cell $(\mathrm{mV})$ \\ from Kim et al. \\ $V_{\text {act.overv. }} \quad$ Activation loss of the stack

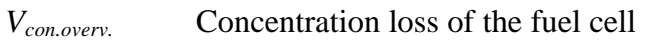 \\ stack (V) \\ Cell voltage (V) \\ $V_{\text {ohm.overv. }} \quad$ Ohmic loss of the fuel cell stack (V) \\ E The maximum theoretical voltage of a \\ stack (V) \\ $V_{\text {stack }} \quad$ Experimental voltage of the fuel cell \\ stack (V)
}

